\title{
OS RÓTULOS DE RAÇõES PODEM AJUDAR A PROMOVER O BEM-ESTAR DE COELHOS?
}

(Can food labels help to promote the welfare of rabbits?)

Zimbábwe Osório-Santos, Maria Júlia Martins Leandro, Belni Sperluk-Belmonte

Universidade Federal de Santa Catarina, Brasil.

*Correspondência: zimbabweosorio@gmail.com

RESUMO: A criação de animais de estimação exóticos ou pets não convencionais têm aumentado, neste grupo inclui-se os coelhos. A introdução de novos animais dentro dos lares humanos exige dos tutores conhecimentos adicionais sobre essas espécies para que o bem-estar de ambos seja assegurado. Os rótulos dos alimentos têm um alto potencial informativo sobre o manejo e bemestar dos pets, já que é um item que os tutores têm contato regularmente. Sendo assim, o objetivo deste trabalho foi investigar a presença de informações referentes ao manejo e bem-estar de coelhos nos rótulos de alimentos completos destinados para essa espécie. De janeiro a julho de 2020, foram fotografados rótulos de alimentos completos para coelhos, comercializados em pet shops e casas agropecuárias em Santa Catarina, nos municípios de Joinville (13 estabelecimentos) e Florianópolis (seis estabelecimentos). As informações dos rótulos que instruíam sobre manejo, saúde e bem-estar de coelhos foram analisadas e interpretadas qualitativamente para extrair o tema do qual relatavam. Os resultados foram interpretados por meio de frequências. Ao todo foram analisados 19 rótulos de 12 marcas distintas. Dos dezenove rótulos quatorze eram indicados para animais de todas as fases de vida, três para coelhos adultos e dois para coelhos filhotes. Sete dos dezenove rótulos também eram indicados para a alimentação de roedores. Usaram a denominação premium ou superpremium onze dos dezenove rótulos. Nove dos dezenove rótulos recomendaram o fornecimento de alimentos ricos em fibras como complementação da ração; fornecimento de água à vontade e limpeza dos comedouros e bebedouros foram orientações encontradas em seis dos dezenove rótulos. Somente cinco dos dezenove rótulos informaram sobre a necessidade de período de adaptação à nova ração. O comportamento animal foi abordado em cinco dos dezenove rótulos; cuidados veterinários e importância do desgaste natural dos dentes foram abordados em três dos dezenove rótulos; dois contraindicaram o fornecimento de algum alimento prejudicial aos animais. Mais da metade dos rótulos não indicou o fornecimento de alimentos ricos em fibras, sabe-se que o fornecimento de alimentos volumosos para coelhos é importante para a saúde intestinal e como enriquecimento ambiental. $\mathrm{O}$ alto teor de amido na alimentação de coelhos tem efeitos adversos na saúde intestinal, porém, em nosso estudo poucos rótulos contraindicaram o fornecimento de qualquer alimento rico em amido. Higienização dos cochos e adaptação à nova dieta são essenciais para assegurar a saúde dos animais, mas estavam presentes na minoria dos rótulos. Recomendações comportamentais foram mais relacionadas ao horário de alimentação e não foi abordado o controle do estresse ou promoção do bem-estar. Informações essenciais sobre o manejo alimentar estavam ausentes na maioria dos rótulos analisados, recomendamos o fornecimento de informações adicionas nos rótulos de rações, como forma de informar os tutores e promover o bem-estar dos coelhos de companhia.

Palavras-chave: cunicultura; animais de companhia; pets; tutores.

Agradecimentos

À Luiz Guilherme Schroeder pelo auxílio na coleta dos dados. 